\title{
A formal vs. a functional approach to Danish clause structure
}

\section{STEN VIKNER \& HENRIK JØRGENSEN}

Diderichsen (1946: 186) proposes two clause models (satningsskemaer) for the analysis of Danish clause structure. In Diderichsen's (1946) main clause model, a Danish main clause consists of three fields (felter), which again consist of a total of seven slots (pladser). In the generative structure that we will advocate here, there are far more subdivisions than there are fields and slots in Diderichsen (1946). Another difference is that there is more asymmetry in the generative analysis: Diderichsen (1946) has many constituents at the same level, whereas the generative analysis generally only allows binary structures. We will show how the more extensive analytical machinery allows for interesting generalisations and predictions in the generative analysis which are not possible in Diderichsen's (1946) clause models. Apart from these differences, we will also discuss three parallels between the two approaches, namely Diderichsen's distinction between topology and syntax, Diderichsen's three fields and what they correspond to in the generative analysis, and finally also the concept of movement of constituents in clause structure. Part of our conclusion will be that all syntacticians/grammarians ought to be prepared to take both the generative and the functional approaches seriously. Even though the tone sometimes can be somewhat polemic, the different approaches have so much in common that they can learn a great deal from each other's results and insights. 